\title{
Long-term lidar observations of wintertime gravity wave activity over northern Sweden
}

\author{
B. Ehard ${ }^{1, *}$, P. Achtert ${ }^{1,2}$, and J. Gumbel ${ }^{1}$ \\ ${ }^{1}$ Department of Meteorology, Stockholm University, Stockholm, Sweden \\ ${ }^{2}$ Department of Applied Environmental Science, Stockholm University, Stockholm, Sweden \\ * now at: Deutsches Zentrum für Luft- und Raumfahrt (DLR), Institut für Physik der Atmosphäre, \\ 82234 Oberpfaffenhofen, Germany \\ Correspondence to: P. Achtert (peggy@misu.su.se)
}

Received: 4 June 2014 - Revised: 13 August 2014 - Accepted: 27 September 2014 - Published: 13 November 2014

\begin{abstract}
This paper presents an analysis of gravity wave activity over northern Sweden as deduced from 18 years of wintertime lidar measurements at Esrange $\left(68^{\circ} \mathrm{N}, 21^{\circ} \mathrm{E}\right)$. Gravity wave potential energy density (GWPED) was used to characterize the strength of gravity waves in the altitude regions $30-40 \mathrm{~km}$ and $40-50 \mathrm{~km}$. The obtained values exceed previous observations reported in the literature. This is suggested to be due to Esrange's location downwind of the Scandinavian mountain range and due to differences in the various methods that are currently used to retrieve gravity wave parameters. The analysis method restricted the identification of the dominating vertical wavelengths to a range from 2 to $13 \mathrm{~km}$. No preference was found for any wavelength in this window. Monthly mean values of GWPED show that most of the gravity waves' energy dissipates well below the stratopause and that higher altitude regions show only small dissipation rates of GWPED. Our analysis does not reproduce the previously reported negative trend in gravity wave activity over Esrange. The observed interannual variability of GWPED is connected to the occurrence of stratospheric warmings with generally lower wintertime mean GWPED during years with major stratospheric warmings. A bimodal GWPED occurrence frequency indicates that gravity wave activity at Esrange is affected by both ubiquitous wave sources and orographic forcing.
\end{abstract}

Keywords. Meteorology and atmospheric dynamics (waves and tides; instruments and techniques)

\section{Introduction}

Planetary waves and gravity waves are responsible for the primary coupling processes between the troposphere and the middle atmosphere (Fritts and Alexander, 2003). Gravity waves play a crucial role in atmospheric circulation, structure, variability, and composition. For instance, a mesospheric pole-to-pole circulation is driven by these waves (Houghton, 1978). The resulting descending flow in the winter hemisphere leads to a warming of the polar winter mesosphere, while the corresponding ascending flow in the summer hemisphere leads to a cooling of the polar summer mesosphere (e.g., Holton and Alexander, 2000; Fritts and Alexander, 2003). Gravity waves are mainly excited in the troposphere and transport energy as well as momentum upwards into the middle atmosphere. Prominent excitation mechanisms for gravity waves are topography, convection, and shears. To enable propagation into the middle atmosphere the phase speed of a gravity wave needs to exceed the mean zonal wind speed or be of opposite direction.

Different techniques are used for the observation and analysis of gravity waves in the lower, middle, and upper atmosphere. These techniques cover certain height ranges and resolve different vertical, horizontal and timescales (Gardner and Taylor, 1998): lidar technique for observation from the troposphere up to the mesosphere (e.g., Gardner et al., 1989; Rauthe et al., 2008; Li et al., 2010), limb sounding satellites from the stratosphere up to the lower mesosphere (e.g., Alexander et al., 2008), radars from the upper troposphere/lower stratosphere or the mesosphere (e.g., Réchou et al., 2013; Wilms et al., 2013), OH-Imagers from the upper mesosphere/lower thermosphere (e.g., Walterscheid et al., 
1999; Suzuki et al., 2010), radiosonde soundings from the troposphere to the lower stratosphere (e.g., Zhang and Yi, 2005), noctilucent cloud images of the upper summer mesosphere (e.g., Pautet et al., 2011), and rocket soundings from the stratosphere to the lower thermosphere (e.g., Rapp et al., 2004).

Lidar is so far the only technique which can provide the temporal and spatial resolution necessary for resolving low and medium frequency gravity waves over the entire altitude range from the troposphere up to the lower thermosphere (Fritts and Alexander, 2003; Rauthe et al., 2008). The longest time series (2002 to 2006) of gravity wave activity measured with lidar was presented by Rauthe et al. (2008) who analyzed data from Kühlungsborn, Germany $\left(54^{\circ} \mathrm{N}, 12^{\circ} \mathrm{E}\right)$.

Wilson et al. (1991) compared lidar measurements of gravity wave activity at Biscarosse $\left(44^{\circ} \mathrm{N}, 1^{\circ} \mathrm{W}\right)$ and Observatoire de Haute Provence $\left(44^{\circ} \mathrm{N}, 6^{\circ} \mathrm{E}\right)$ from 1986 to 1989. Sivakumar et al. (2006) analyzed lidar data from 1998 to 2002 measured at Gadanki, India $\left(13^{\circ} \mathrm{N}, 79^{\circ} \mathrm{E}\right)$. Thurairajah et al. (2010b) analyzed data from Chatanika, Alaska $\left(65^{\circ} \mathrm{N}\right.$, $147^{\circ} \mathrm{W}$ ) from 2002 to 2005 while Yamashita et al. (2009) analyzed data measured at Rothera Antarctic research station $\left(67^{\circ} \mathrm{S}, 68^{\circ} \mathrm{W}\right)$ from 2002 to 2005 and at the South Pole $\left(90^{\circ} \mathrm{S}\right)$ from 1999 to 2001 . Selected case studies of gravity wave activity were presented by Whiteway and Carswell (1994), Blum et al. (2004), and Taori et al. (2012).

Gravity wave activity calculated from lidar measurements is commonly based on deviations from a background temperature or density profile (Rauthe et al., 2008). These measurements generally show a larger gravity wave activity during winter than during summer (e.g., Wilson et al., 1991; Rauthe et al., 2008). Table 1 provides an overview over gravity wave activity as measured at altitude ranges of 30-40 and $40-50 \mathrm{~km}$ at different locations. Most of the observations were conducted in the Northern Hemisphere. There are only few measurement stations to provide such data at mid and low latitudes in the Southern Hemisphere. Highest gravity wave activity is observed at high latitudes in the Northern Hemisphere. This is in agreement with satellite studies which showed stronger gravity wave activity at mid and high latitudes during winter than during summer (Alexander et al., 2008). Measurements at the South Pole are significantly lower than those at northern high latitudes (Yamashita et al., 2009). It was also found that gravity wave activity is decreased during stratospheric warmings (Whiteway and Carswell, 1994; Blum et al., 2004).

This paper presents long-term measurements of gravity wave activity, measured between November and March, over northern Sweden. We focus on monthly and year-to-year variability, the dominant vertical wavelength, the gravity wave potential energy density, and the altitude range of gravity wave dissipation. The Esrange lidar $\left(68^{\circ} \mathrm{N}, 21^{\circ} \mathrm{E}\right)$ data set is one of the longest time series in the Arctic and currently spans over 18 winters. The instrument is located east of the Scandinavian mountain ridge; thus, measurements are strongly influenced by orographically induced gravity waves. Gravity wave parameters are calculated between 30 and $65 \mathrm{~km}$ altitude. Altogether, more than $1500 \mathrm{~h}$ of measurements are examined and presented in this study.

We begin this paper with a brief description of the Esrange lidar and its 18 year data set in Sect. 2. The derived long-term statistics and a comparison to previous publications of gravity wave activity are presented in Sect. 3. The study ends with a discussion of our findings in Sect. 4 and our conclusions in Sect. 5.

\section{Methodology}

\subsection{The Esrange lidar}

The Department of Meteorology of the Stockholm University operates a lidar system at Esrange $\left(68^{\circ} \mathrm{N}, 21^{\circ} \mathrm{E}\right)$ in northern Sweden, about $150 \mathrm{~km}$ north of the polar circle. It was originally installed in 1997 by the University of Bonn. The Esrange lidar uses a pulsed frequency-doubled Nd:YAG (neodymium-doped yttrium aluminium garnet) solid-state laser operating at $532 \mathrm{~nm}$ wavelength as light source. The pulse energy of the laser was $350 \mathrm{~mJ}$ from 1997 to 2012 and since 2012 it has been $900 \mathrm{~mJ}$ (Achtert et al., 2013). The effective telescope diameter is $866 \mathrm{~mm}$ (Blum and Fricke, 2005). A detection range gate of $1 \mu$ s results in a vertical resolution of $150 \mathrm{~m}$. The lidar covers an altitude range from 4 to $80 \mathrm{~km}$.

General details about the instruments are provided in Blum and Fricke (2005) and Achtert et al. (2013). Measurements with the Esrange lidar are conducted on a campaign basis. The instrument has previously been used for studies of polar stratospheric clouds (Achtert and Tesche, 2014; Blum et al., 2005), noctilucent clouds (Stebel et al., 2000), waves in the middle atmosphere (Blum et al., 2004), middle atmospheric temperature (Blum and Fricke, 2008), and as a support for rocket and balloon campaigns at Esrange (Lossow et al., 2009).

\subsection{Temperature profiling}

Temperature measurements with the Esrange lidar are performed using the integration technique between 30 and $80 \mathrm{~km}$ since January 1997. The implementation of rotationalRaman channels in November 2010 extended this range down to $4 \mathrm{~km}$ (Achtert et al., 2013). The integration technique can only be applied if the hydrostatic equilibrium equation and the ideal gas law are valid. It involves integrating the relative density profile in an aerosol-free atmosphere downward using an initial temperature guess as an upper boundary. The initial temperature is taken from the MSIS 86 model (Hedin, 1991) at a reference altitude at which the nightly mean count rate is four counts higher than the background count rate. This reference altitude is typically located between 70 and $80 \mathrm{~km}$. The rotational-Raman technique allows 
Table 1. Mean GWPED for different altitude regions during winter.

\begin{tabular}{|c|c|c|c|c|c|c|c|}
\hline & \multirow[t]{2}{*}{ Location } & \multirow[t]{2}{*}{$\begin{array}{l}\text { period of } \\
\text { interest }\end{array}$} & \multicolumn{2}{|c|}{$\begin{array}{l}\text { GWPED per volume } \\
{\left[\mathrm{J} \mathrm{m}^{-3}\right]}\end{array}$} & \multicolumn{3}{|c|}{$\begin{array}{c}\text { GWPED per mass } \\
{\left[\mathrm{J} \mathrm{kg}^{-1}\right]}\end{array}$} \\
\hline & & & $30-40 \mathrm{~km}$ & $40-50 \mathrm{~km}$ & $30-40 \mathrm{~km}$ & $40-50 \mathrm{~km}$ & $30-45 \mathrm{~km}$ \\
\hline Alexander et al. (2011) & $69^{\circ} \mathrm{S}, 78^{\circ} \mathrm{E}$ & May-September & & 0.021 & & 17.7 & \\
\hline Blum et al. (2004) & $\begin{array}{l}68^{\circ} \mathrm{N}, 21^{\circ} \mathrm{E} \\
69^{\circ} \mathrm{N}, 16^{\circ} \mathrm{E}\end{array}$ & $\begin{array}{l}\text { 19-20 Jan } 2003 \\
19-20 \text { Jan } 2003\end{array}$ & $\begin{array}{l}0.436 \\
0.207\end{array}$ & $\begin{array}{l}0.042 \\
0.029\end{array}$ & & & \\
\hline Rauthe et al. (2008) & $54^{\circ} \mathrm{N}, 12^{\circ} \mathrm{E}$ & Nov-Jan & 0.026 & 0.020 & & & \\
\hline Sivakumar et al. (2006) & $13^{\circ} \mathrm{N}, 79^{\circ} \mathrm{E}$ & Nov-Feb & & & 15.4 & 31.4 & \\
\hline Taori et al. (2012) ${ }^{\mathrm{a}}$ & $\begin{array}{l}13^{\circ} \mathrm{N}, 79^{\circ} \mathrm{E} \\
18^{\circ} \mathrm{N}, 67^{\circ} \mathrm{W}\end{array}$ & $\begin{array}{l}7-10 \text { Dec } 2009 \\
7-10 \text { Dec } 2009\end{array}$ & & & $\begin{array}{l}(2.6) 14.8 \\
(0.3) 4.8\end{array}$ & $\begin{array}{l}\text { (1.6) } 29.8 \\
(0.4) 9.7\end{array}$ & \\
\hline Thurairajah et al. (2010a) ${ }^{b}$ & $\begin{array}{l}65^{\circ} \mathrm{N}, 147^{\circ} \mathrm{W} \\
67^{\circ} \mathrm{N}, 51^{\circ} \mathrm{W} \\
54^{\circ} \mathrm{N}, 12^{\circ} \mathrm{E}\end{array}$ & $\begin{array}{c}\text { Jan-Feb } 2008 \\
\text { Jan-Feb } 2008 \\
\text { Jan-Feb } 2008\end{array}$ & & & & $\begin{array}{l}1.6 \\
4.7 \\
2.6\end{array}$ & \\
\hline Thurairajah et al. $(2010 b)^{b}$ & $65^{\circ} \mathrm{N}, 147^{\circ} \mathrm{W}$ & Dec-Feb & & & & 2.6 & \\
\hline Whiteway and Carswell (1994) & $80^{\circ} \mathrm{N}, 86^{\circ} \mathrm{W}$ & $\begin{array}{l}\text { Feb-Mar } 1993^{\mathrm{c}} \\
\text { Feb-Mar } 1993^{\mathrm{d}}\end{array}$ & $\begin{array}{l}0.057 \\
0.112\end{array}$ & $\begin{array}{l}0.017 \\
0.050\end{array}$ & $\begin{array}{l}8.7 \\
14.5\end{array}$ & $\begin{array}{l}8.6 \\
26.0\end{array}$ & $\begin{array}{l}9.5 \\
17.7\end{array}$ \\
\hline Whiteway and Carswell (1995) & $44^{\circ} \mathrm{N}, 80^{\circ} \mathrm{W}$ & $\begin{array}{l}\text { Jan } 1992 \\
\text { Mar } 1992\end{array}$ & & $\begin{array}{l}0.025 \\
0.009\end{array}$ & & $\begin{array}{l}13.9 \\
5.24\end{array}$ & \\
\hline Wilson et al. (1991) & $\begin{array}{l}44^{\circ} \mathrm{N}, 1^{\circ} \mathrm{W} \\
44^{\circ} \mathrm{N}, 6^{\circ} \mathrm{E}\end{array}$ & $\begin{array}{l}\text { Dec-Feb } \\
\text { Dec-Feb }\end{array}$ & & & & & $\begin{array}{l}7.1 \\
11.9\end{array}$ \\
\hline Yamashita et al. (2009) & $\begin{array}{l}90^{\circ} \mathrm{S} \\
67^{\circ} \mathrm{S}, 68^{\circ} \mathrm{W}\end{array}$ & $\begin{array}{l}\text { May-Aug } \\
\text { May-Aug }\end{array}$ & & & & & $\begin{array}{l}2.7 \\
10.9\end{array}$ \\
\hline
\end{tabular}

${ }^{a}$ The numbers in brackets are the minimum values; whereas the others are the maximum values. ${ }^{b}$ GWPED lowered by a factor of 1.7 due to data filtering. ${ }^{c}$ Cases they did associate with stratospheric warmings. ${ }^{\mathrm{d}}$ Cases they did not associate with stratospheric warmings.

for a retrieval of temperature profiles under conditions that inhibit the application of the integration technique, i.e., in the presence of aerosol and cloud layers. A comprehensive overview of common techniques for temperature measurements with lidar has been presented by Behrendt (2005).

An example of a nightly mean temperature profile as derived from a measurement with the Esrange lidar between 17:30 and 03:30 UT on 6-7 March 1998 night is shown in Fig. 1a. The measurement uncertainty (including the effect of the photomultiplier dark count rate and one standard deviation of the measurements) is generally below $\pm 5 \mathrm{~K}$ for a nightly mean temperature profile in the height range between 30 and $65 \mathrm{~km}$. The bias due to the initialization of the integration technique depends on the estimated initial temperature value. This bias decreases with increasing density, i.e., exponentially with decreasing altitude with the atmospheric scale height of $\approx 7 \mathrm{~km}$. By assuming that the initial temperature in the presence of gravity waves could have been wrong by up to $\pm 20 \mathrm{~K}$ (Rauthe et al., 2008) when starting to integrate at $70 \mathrm{~km}$ height we can conclude that at an altitude of $65 \mathrm{~km}$ this bias decreased to $\pm 10 \mathrm{~K}$ and at $49 \mathrm{~km}$ it decreased even further to $\pm 1 \mathrm{~K}$.

\subsection{Gravity waves in lidar measurements}

In this study lidar measurements are used to characterize gravity wave activity in the upper stratosphere/lower mesosphere based on fluctuations around a background temperature profile. The latter is obtained by applying a smoothing spline fit to the nightly mean temperature profile (black line in Fig. 1b). By using the smoothed nightly mean temperature profile as background temperature, waves with low phase speeds are included in our gravity wave analysis. Furthermore, hourly mean temperature profiles with a stepwise shift in the integration time of $15 \mathrm{~min}$ are derived from the individual lidar measurements (colored lines in Fig. 1b). These hourly profiles are vertically smoothed (running mean) with a window length of $2 \mathrm{~km}$. To estimate the temperature deviation, the background temperature profile is subtracted from the individual hourly mean profiles. The temperature perturbations for the lidar measurement on 6 March 1998 are shown as an Hofmüller diagram in Fig. 1c. The mean absolute value between 40 and $50 \mathrm{~km}$ altitude of the temperature perturbations shown in Fig. 1c is $2.5 \mathrm{~K}$. The Hofmüller diagram illustrates the descending motion of positive and negative temperature fluctuations. This descending motion 

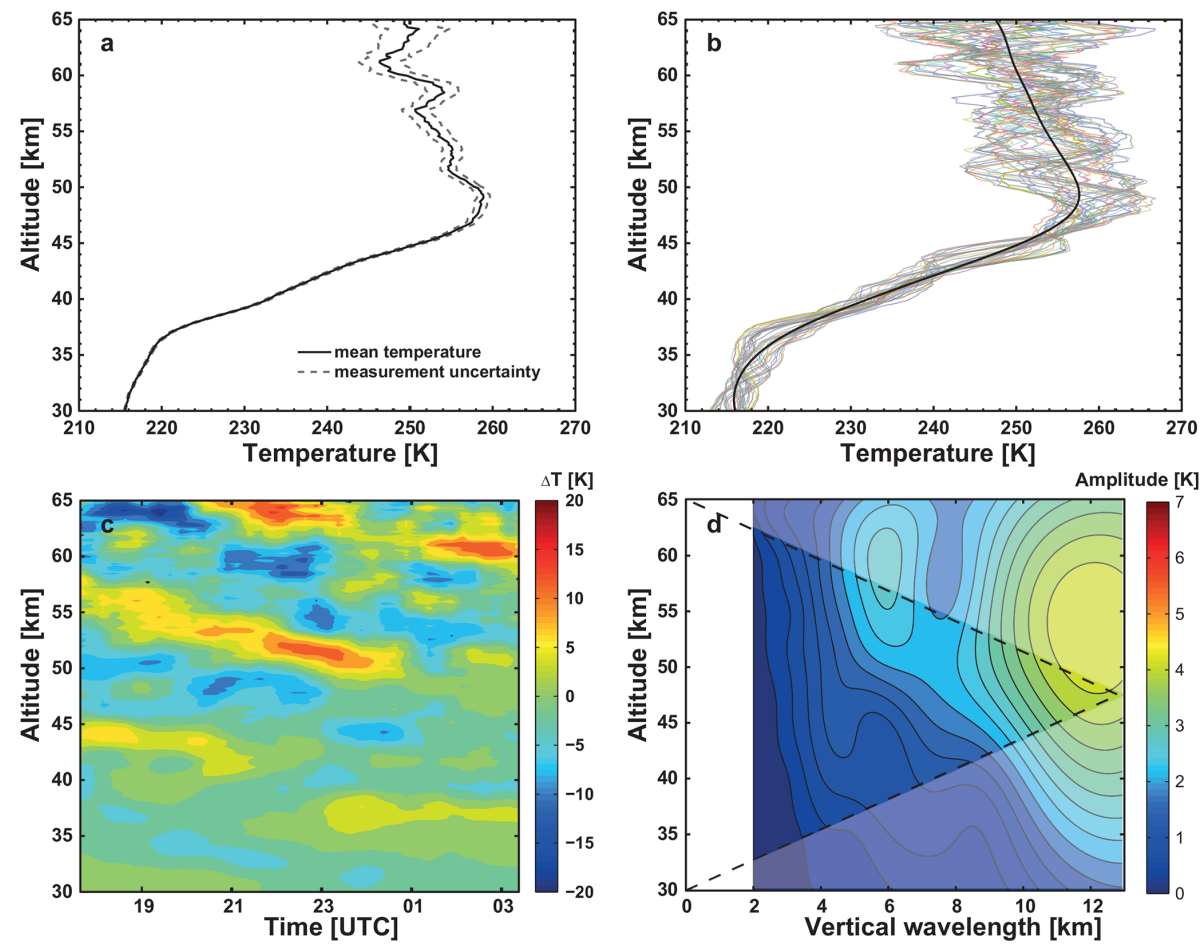

Figure 1. (a) Temperature profile (black) and uncertainty (dashed) as derived from a lidar measurement on 6 March 1998 between 17:30 and 03:30 UT. (b) Temperature profile averaged over the entire measurement period after applying a moving spline fit (black line) and individual one hour mean profiles derived by moving the averaging window in step of 15 minutes (colored lines). (c) Hofmüller diagram of the temperature perturbations during the measurement period. (d) Mean wavelet spectrum with the amplitudes color-coded as a function of vertical wavelength and altitude. The gray shaded area marks results that are influenced by edge effects (cone of influence).

represents gravity waves with a downward phase velocity which is linked via the dispersion relationship of gravity waves to an upward directed group velocity which in turn is associated with upward propagating gravity waves (Fritts and Alexander, 2003).

The vertical wavelength of the gravity waves was retrieved by performing a spectral analysis in form of a wavelet transformation with a Morlet wavelet of the sixth order (Torrence and Compo, 1998). Information on the dominant vertical wavelengths $\lambda_{z}$ are defined as the peaks of the global wavelet spectra for every single temperature perturbation profile. In contrast to a standard Fourier transformation which only leads to the dominant wavelength, the wavelet transformation also identifies the altitude at which the dominant wavelength occurs. Figure 1d shows the result of the wavelet transformation for the example measurement. Shown is the amplitude of different vertical wavelengths as a function of altitude. Two dominant waves at approximately 6 and $12 \mathrm{~km}$ vertical wavelength can be identified. The black dashed line in Fig. 1d marks the so-called cone of influence (see Torrence and Compo, 1998, for detailed information). Everything to the right hand side of the cone of influence (gray shaded area) is influenced by edge effects resulting from the finite length of the analyzed altitude range.
By limiting the gravity wave analysis to the height range between 30 and $65 \mathrm{~km}$ a balance of accurate results and spectral resolution is ensured. The signal strength, and thus the observable height range, can vary quite strongly during a measurement as a reaction to changes in tropospheric cloudiness, laser power, or beam alignment. These factors have been accounted for during the performance and analysis of measurements with the Esrange lidar. To ensure that the signal to noise ratio at $65 \mathrm{~km}$ is sufficient for applying the integration technique from this altitude or above only individual profiles (integration of 5000 laser shots; about $4.1 \mathrm{~min}$ ) were used for which the mean counts at $40 \mathrm{~km}$ height exceeded a value of 450 counts integrated over 5000 laser shots. Additionally, individual measurements had to be at least 2 hours long to be used to derive gravity wave perturbations from the background profile. These quality assurance criteria together with the vertical smoothing of the individual temperature profiles limit the retrieval to vertical wavelengths in the range from 2 to $13 \mathrm{~km}$. The lower and upper boundaries are defined by the smoothing window and the spectral analysis (cone of influence), respectively. Waves with a wavelength between 2.0 and $2.5 \mathrm{~km}$ experience significant damping introduced by the smoothing process. 


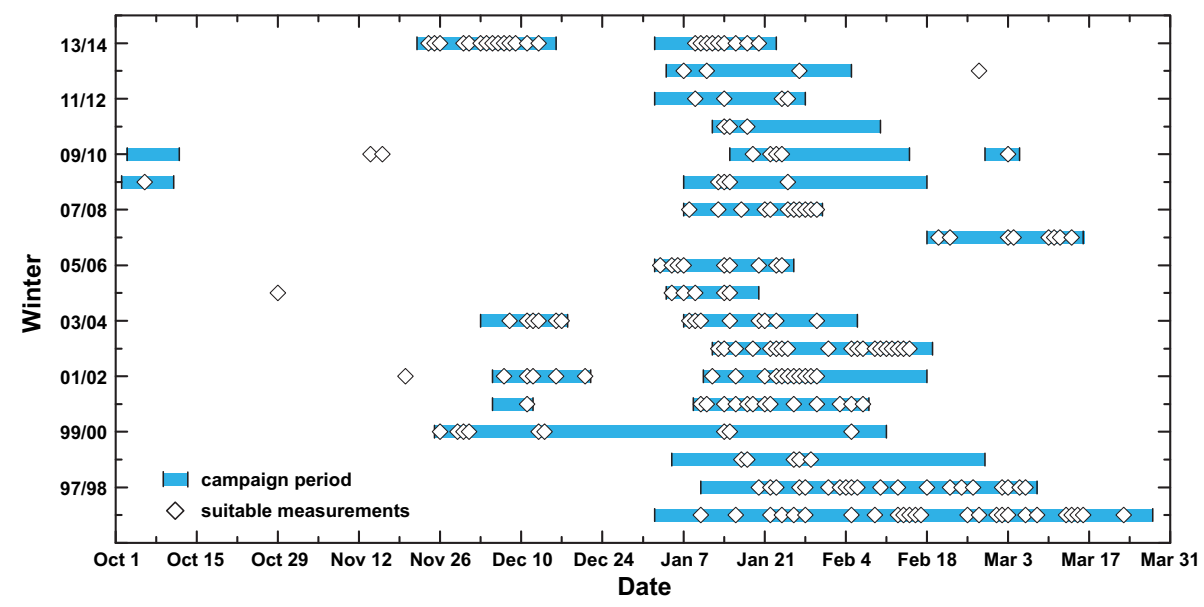

Figure 2. Range of measurement campaigns (marked by colored bars) and nights with suitable measurements for gravity wave analysis (diamonds).

To ensure that the atmosphere is in steady state during the analyzed periods and to avoid strong temperature perturbations which are not due to gravity waves but tides or changes in the synoptic situation, measurements were partitioned into multiple periods during which the background temperature profiles showed little variation. This procedure is especially important since Esrange is often located right at the edge of the polar vortex (Harvey et al., 2002). Consequently, extensive measurements periods can contain situations in which the Esrange lidar observes atmospheric volumes that are located both inside and outside of the polar vortex and, thus, show corresponding changes in the background temperature profile. Note, that this partitioning only reduces the influence of tides and does not exclude them completely from our analysis. Also long period gravity waves are still present in our analysis during the longer measurement nights.

A common way to quantify gravity wave activity is to calculate the gravity wave potential energy density (GWPED),

$$
\begin{aligned}
& E_{\text {pot,volume }}=\bar{\rho} \frac{1}{2} \frac{g^{2}}{N^{2}} \overline{\left(\frac{\widetilde{\rho}}{\bar{\rho}}\right)^{2}} \approx \bar{\rho} \frac{1}{2} \frac{g^{2}}{N^{2}} \overline{\left(\frac{\widetilde{T}}{\bar{T}}\right)^{2}} \\
& E_{\text {pot,mass }}=\frac{E_{\text {pot,volume }}}{\bar{\rho}},
\end{aligned}
$$

with the fluctuations of density $\tilde{\rho}$ and temperature $\widetilde{T}$, the mean density $\bar{\rho}$, temperature $\bar{T}$, the Brunt-Väisälä frequency $N$, and the gravitational constant $g$. The substitution of relative density perturbations by relative temperature perturbations in Eq. (1) assumes hydrostatic balance, which is a justified approximation throughout the middle atmosphere. A higher gravity wave activity would induce stronger temperature (density) fluctuations from the background leading to an increase in GWPED per volume. The energy flux $\left(E_{\text {flux }}=c_{\mathrm{g}} E_{\mathrm{pot}}\right)$ cannot be obtained from lidar measurements alone, since the group velocity $c_{\mathrm{g}}$ is unknown. Under the assumption of upward wave propagation GWPED per volume is approximately constant with altitude if there is no dissipation or input of wave energy. Thus, if the energy flux cannot be determined from the measurements, GWPED can be used instead as an indicator for altitude ranges at which dissipation occurs. However, the GWPED cannot be used to distinguish between cases of wave dissipation and wave refraction. Note, in case of wave refraction, the energy is exchanged between the waves field and the mean wind profile. Furthermore the values of GWPED are affected by the smoothing of the individual temperature profiles. A larger smoothing window results in lower temperature perturbations and hence a lower GWPED. A more detailed discussion about using GWPED for the quantification of gravity wave activity can be found in Rauthe et al. (2008).

For this study the mean density $\bar{\rho}$ is taken from the MSIS 86 model (Hedin, 1991), whereas the Brunt-Väisälä frequency $N$ is derived from the background temperature profile. The temperature perturbations $\widetilde{T}$ are the previously described deviations from the background temperature profile. As mean temperature $\bar{T}$ the smoothed nightly mean temperature is used. To derive the mean GWPED during one measurement period, the mean value of the relative temperature perturbations squared is calculated. For the previously discussed case of the 6 March 1998 a mean Brunt-Väisälä frequency $N$ of $0.019 \mathrm{~s}^{-1}$ was deduced between 40 and $50 \mathrm{~km}$, resulting in a mean GWPED per volume (per mass) of $0.031 \mathrm{~J} \mathrm{~m}^{-3}\left(22.5 \mathrm{~J} \mathrm{~kg}^{-1}\right)$ for the same altitude region.

The described methodology of obtaining gravity wave parameters was applied to all data obtained with the Esrange lidar during Arctic winter (between October and March) in the time period from 1996/1997 to 2013/2014. This corresponds to 386 days of measurements within 18 years. However, not all days were found suitable for the gravity wave analysis as the lidar data have to satisfy the conditions described above. An overview of the distribution of the 213 nights $(1500 \mathrm{~h}$ ) of measurements that were used in this study is given in Fig. 2. 


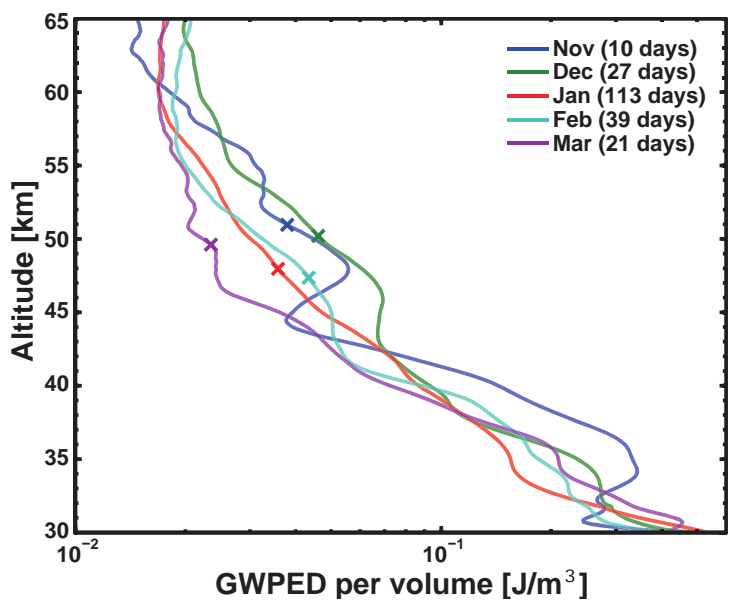

Figure 3. Mean GWPED per volume profiles during different winter months. The crosses mark the respective mean stratopause height. The number of days considered in the monthly mean profile are given in the brackets.

\section{Results}

The focus of the analysis presented here is on the impact of gravity waves within the height range of 30 to $65 \mathrm{~km}$. As discussed in Sect. 2 only vertical wavelengths with lengths between 2 and $13 \mathrm{~km}$ are detectable due to the finite observable height range defined by the lidar measurements. The derived occurrence frequency of the vertical wavelength of the analyzed data set showed no preferred dominant vertical wavelength (not shown). The only exception can be seen at short wavelengths (smaller than $3 \mathrm{~km}$ ), which show a significant lower occurrence frequency since they are damped due to the smoothing of the individual temperature profiles.

Figure 3 shows profiles of the mean GWPED per volume during different months between 30 and $65 \mathrm{~km}$ altitude. The GWPED per volume is approximately constant (i.e no dissipation of wave energy) for all months above $\approx 45 \mathrm{~km}$ altitude. Downward of that height region the energy increases by almost one order of magnitude. This height range is generally lower than the monthly mean stratopause height which is denoted by the crosses in Fig. 3. The monthly mean stratopause height is derived from the lidar measurements by assuming that the stratopause coincides with the height of the maximum temperature in the background temperature profile between 30 and $65 \mathrm{~km}$, e.g., an altitude of $48 \mathrm{~km}$ in Fig. $1 \mathrm{a}$.

Figure 3 shows that the GWPED per volume is generally higher during November and December than during January and February. This is also visible in the monthly mean values of the GWPED per volume between 30 and $40 \mathrm{~km}$ and between 40 and $50 \mathrm{~km}$ presented in Table 2. The GWPED per volume shows a decrease in both altitude regions during January and February. However, in the higher altitude region (40 to $50 \mathrm{~km}$ ) the GWPED per volume increases from February to March while it decreases in the lower altitude region (30

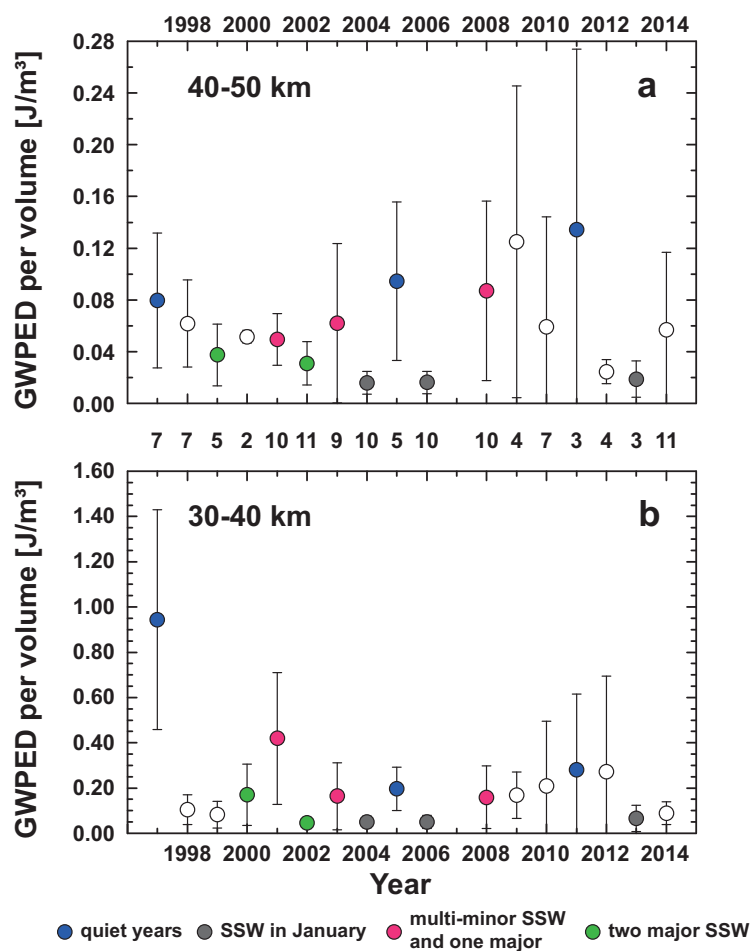

Figure 4. Monthly mean GWPED per volume and corresponding standard deviations during January measured between $40-50 \mathrm{~km}$ (a) and $30-40 \mathrm{~km}$ (b), respectively. Numbers between the two plots refer to the number of available measurement days per year. The color coding marks the occurrence of stratospheric warmings as listed by Chandran et al. (2014)

to $40 \mathrm{~km}$ ). This feature is also visible in the GWPED profiles presented in Fig. 3. Up to an altitude of $37 \mathrm{~km}$ the GWPED per volume in March is higher than in January and February. This feature is reversed above $37 \mathrm{~km}$ height.

To determine if there is any trend visible in gravity wave activity during the years, we calculated the mean GWPED per volume between 30 and $40 \mathrm{~km}$ and 40 and $50 \mathrm{~km}$ during January for all years. We chose January since this is the month with the highest number of measurements (see Figs. 2 and 3). Figure 4 shows that the GWPED during January varies strongly during different years in both altitude regions with the lower GWPED values coinciding with stratospheric warming events (color coding in Fig. 4). However, no clear trend can be inferred from the data set.

Figure 5 presents the occurrence frequency of GWPED per volume for the $30-40 \mathrm{~km}$ altitude range and the time period from November to March. The occurrence frequencies are used to assess the representativeness of the mean values of GWPED. We generally find a bimodal distribution that indicates two distinct states of gravity wave activity over Esrange. The first of the corresponding two Gaussian modes (thick solid line in Fig. 5) centers at a value of $0.050 \pm 0.001 \mathrm{~J} \mathrm{~m}^{-3}$. That is almost by a factor of 4 lower 
Table 2. Monthly mean GWPED per volume $\left[\mathrm{J} \mathrm{m}^{-3}\right]$ and standard deviation for different altitude intervals. The number of measurement days comprising the mean value are the same as in Fig. 3.

\begin{tabular}{lccccc}
\hline height range & Nov & Dec & Jan & Feb & Mar \\
\hline $30-40 \mathrm{~km}$ & $0.28 \pm 0.25$ & $0.22 \pm 0.26$ & $0.20 \pm 0.31$ & $0.20 \pm 0.20$ & $0.23 \pm 0.22$ \\
$40-50 \mathrm{~km}$ & $0.06 \pm 0.08$ & $0.06 \pm 0.05$ & $0.05 \pm 0.06$ & $0.05 \pm 0.05$ & $0.04 \pm 0.04$ \\
\hline
\end{tabular}

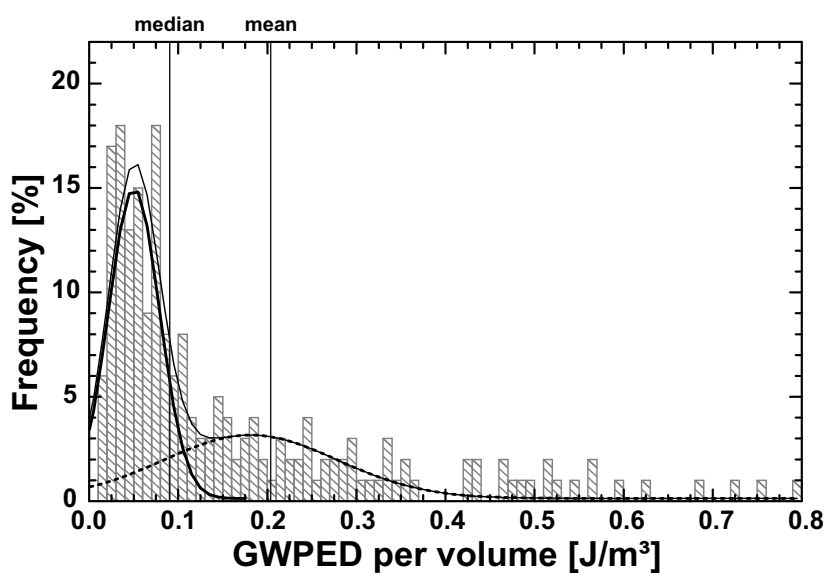

Figure 5. Histogram of the occurrence frequency of the GWPED per volume measured between November and March in the height range from 30 to $40 \mathrm{~km}$. Two Gaussian modes are fitted to the distribution (thick and dashed line), while the thin line denotes the sum of the two fits.

than the mean value of $0.203 \mathrm{~J} \mathrm{~m}^{-3}$ that is derived from averaging over all data points. The center of the second Gaussian mode (thick dashed line) with a value of $0.182 \pm 0.020 \mathrm{~J} \mathrm{~m}^{-3}$ is rather close to the overall mean value as it accounts for the cases with very high GWPED.

Table 3 shows the mean GWPED per volume and per mass as derived from Esrange lidar measurements between 30-40, $40-50$, and $30-45 \mathrm{~km}$, respectively. For comparison to the results presented by Rauthe et al. (2008), the GWPED is calculated for two different time periods, November to March and November to January. Further, Table 3 provides an overview of the overall mean values and center of the two Gaussian modes as derived for different altitude ranges and time periods, following the example described for Fig. 5. In general the first Gaussian mode centers at values that are by a factor between 2 and 4 lower than the mean values derived from averaging over all data points.

\section{Discussion}

Our findings on gravity wave activity generally agree with previous studies and furthermore enable a new level of quantification. The equally distributed spectrum of vertical wavelengths indicates that wave excitation mechanisms around Esrange induce no preferred vertical wavelength. It also indicates that there is no mechanism that selectively prevents waves with a certain vertical wavelength between 2 and $13 \mathrm{~km}$ from propagating into the middle atmosphere. This is in agreement with Chane-Ming et al. (2000) who provided an overview over gravity wave parameters measured with various instruments at different stations.

Figure 3 shows that the largest variation in GWPED with altitude is found below the stratopause during all months. This indicates that, under the assumption of upward gravity wave propagation, most of the gravity waves' energy is already dissipated below the stratopause, either due to critical level filtering or due to wave breaking. Both processes could explain the general form of the GWPED curve during winter, with a lower GWPED during January and February compared to the rest of the season (compare Fig. 3 and Table 2). During January and February stratospheric warmings can generally be observed in the Arctic. Stratospheric warmings are characterized by a reversal of the zonal-mean flow in the stratosphere disrupting the polar vortex and leading to a warming of the stratosphere and a cooling of the mesosphere. A recent review of stratospheric warmings can be found in Chandran et al. (2014). The change in the zonal-mean zonal wind direction from westerly to easterly marks a change in critical level filtering of gravity waves, and thus, affects the GWPED. Thurairajah et al. (2010a) measured a lower GWPED during and after stratospheric warming events. Consequently, the lower GWPED over Esrange during January and February compared to the rest of the winter is most likely to be the result of the influence of stratospheric warmings. Note, that Whiteway and Carswell (1994) also reported a lower GWPED in the presence of stratospheric warmings, but Duck et al. (1998) noted that Whiteway and Carswell (1994) wrongly associated a movement of the polar vortex with a stratospheric warming.

The transition of the mean stratospheric circulation from eastward to westward flow during March and the associated change in critical level filtering decrease the GWPED at high altitudes. This can be seen in an altitude region above $37 \mathrm{~km}$ (Fig. 3 and Table 2), but not below. This differs from 
Table 3. Mean with standard deviation, median, and Gaussian mode values of GWPED for different altitude regions, derived from measurements with the Esrange lidar.

\begin{tabular}{|c|c|c|c|c|c|}
\hline & \multicolumn{2}{|c|}{$\begin{array}{l}\text { GWPED per volume } \\
{\left[\mathrm{J} \mathrm{m}^{-3}\right]}\end{array}$} & \multicolumn{3}{|c|}{$\begin{array}{c}\text { GWPED per mass } \\
{\left[\mathrm{J} \mathrm{kg}^{-1}\right]}\end{array}$} \\
\hline & $30-40 \mathrm{~km}$ & $40-50 \mathrm{~km}$ & $30-40 \mathrm{~km}$ & $40-50 \mathrm{~km}$ & $30-45 \mathrm{~km}$ \\
\hline \multicolumn{6}{|c|}{ November to March } \\
\hline mean & $0.203 \pm 0.268$ & $0.053 \pm 0.055$ & $30.2 \pm 37.8$ & $40.2 \pm 39.2$ & $31.8 \pm 33.8$ \\
\hline median & 0.091 & 0.036 & 15.3 & 28.1 & 18.8 \\
\hline mode 1 & 0.050 & 0.023 & 8.0 & 15.6 & 9.7 \\
\hline mode 2 & 0.182 & 0.053 & 25.5 & 39.9 & 29.8 \\
\hline & \multicolumn{5}{|c|}{ November to January } \\
\hline mean & $0.198 \pm 0.280$ & $0.056 \pm 0.011$ & $30.6 \pm 40.4$ & $43.7 \pm 41.9$ & $33.2 \pm 37.1$ \\
\hline median & 0.084 & 0.038 & 13.3 & 31.0 & 19.1 \\
\hline mode 1 & 0.051 & 0.019 & 8.9 & 15.1 & 9.5 \\
\hline mode 2 & 0.169 & 0.054 & 32.1 & 40.2 & 27.3 \\
\hline
\end{tabular}

January conditions where stratospheric warmings are likely to cause a general reduction in GWPED also below $37 \mathrm{~km}$. A possible explanation for this behavior is that stratospheric warmings influence the stratospheric circulation on shorter timescales than the gradual shift from winter to summer circulation. Thus, the filtering mechanism induced by the change in background wind, affects the monthly mean GWPED during March at higher altitude regions.

No trend in GWPED can be deduced from Fig. 4. This is in disagreement with suggestions of Blum and Fricke (2008) who also analyzed measurements of GWPED with the Esrange lidar. However, the authors analyzed a shorter time series that only spanned years from 1997 to 2005 . Any trend deduced from this data set vanishes if longer time periods are considered.

Examining the interannual variability of the GWPED during January presented in Fig. 4 one can see a certain correlation with stratospheric warming events. During years with major stratospheric warmings a very low gravity wave activity is detected (grey and green dots in Fig. 4), whereas during quiet years (blue dots) a higher gravity wave activity is detected in January. This reduction of GWPED during stratospheric warmings was earlier noted by Thurairajah et al. (2010a). Due to the stratospheric wind reversal during a stratospheric warming the filtering of gravity waves is changed resulting in the lower values which can be seen during these winters. Note, that the winters associated with multiple minor stratospheric warmings and one major stratospheric warming (red dots in Fig. 4) do not follow this characterization. This could be caused by a less efficient filtering of gravity waves during minor stratospheric warmings compared to major stratospheric warmings. This will be investigated further in a future study.

In order to evaluate whether there are geographically induced differences in gravity wave forcing, we compared our findings to the literature. Mean values of GWPED as obtained by lidars at several different locations are presented in Table 1. Most of the available values originate from observations conducted in the Northern Hemisphere. Only few measurements exist for mid and low latitudes in the Southern Hemisphere. Also, there are only few long-term lidar studies of GWPED, i.e., Rauthe et al. (2008) (5 years) and Thurairajah et al. (2010b) (4 years). The values of GWPED presented in this paper exceed most published measurements in Table 1 . The only values that are higher than our findings are reported by Blum et al. (2004). However, these are the result of dedicated case studies at Esrange and Andøya. It is possible that single extreme events show a higher GWPED than the long-term mean we present here. In general, the highest values are observed at high latitudes in the Northern Hemisphere, i.e., our results, those of Blum et al. (2004), and the values of Whiteway and Carswell (1994) which they did not associate with stratospheric warmings.

The observations of Thurairajah et al. (2010b) and Thurairajah et al. (2010a) for lidar stations north of $60^{\circ} \mathrm{N}$ together with those of Yamashita et al. (2009) from $90^{\circ} \mathrm{S}$ present the lowest GWPED. They compare better to observations at mid-latitudes presented by Rauthe et al. (2008) and Whiteway and Carswell (1995) rather than those at high latitudes in the Northern Hemisphere. The low values of Thurairajah et al. (2010b, a) also result from a different approach to obtain GWPED. Additionally, a different filtering and smoothing of the density profiles compared to our methodology causes a decrease in GWPED of a factor of 1.7 (Thurairajah et al., 2010b). Accounting for this factor does not lead to a harmonization of the findings. This is likely to be an effect of Esrange's location downstream of the Scandinavian mountain ridge which substantially increases the potential for observing higher gravity wave activity (Zhang et al., 2012). 
The decrease of GWPED from high latitudes (larger than $\left.60^{\circ} \mathrm{N}\right)$ to mid latitudes $\left(60-30^{\circ} \mathrm{N}\right)$ with intermittent values at low latitude sites (lower than $30^{\circ} \mathrm{N}$ ) is consistent with satellite observations. Alexander et al. (2008) evaluated the change of zonally averaged temperature perturbations with latitude and height and found the largest temperature perturbations associated with the largest GWPED at high latitudes in the winter hemisphere, a decrease in temperature perturbations at mid-latitudes, and intermediate values at low latitudes.

Figure 5 presents the occurrence frequency of GWPED for the $30-40 \mathrm{~km}$ altitude range and the time period from November to March. The GWPED of the first Gaussian mode presented in Table 3 agrees with the mean values of Alexander et al. (2011), Rauthe et al. (2008), and the January values of Whiteway and Carswell (1995). None of the locations examined in those studies are close to a strong source of mountain waves. Consequently, the first Gaussian mode in the GWPED occurrence frequency can be interpreted as representative of gravity waves excited by ubiquitous sources such as convection, shears, geostrophic adjustment, or wave-wave interactions. The second Gaussian mode found at Esrange could then be associated with strong mountain wave forcing or associated with stronger winds at the edge of the polar vortex (Duck et al., 1998). Since the distribution of GWPED is similar during all winter months (not shown) it is more likely that the shape of the distribution is controlled by mountain waves and not by the presence of the polar vortex. Otherwise a different shape would be expected during November than e.g., during January.

Most cases in Fig. 5 show a GWPED below the mean value. This is due to the bimodal distribution of GWPED occurrence and the corresponding high bias of the mean value, i.e., few cases with strong wave activity shift the mean towards higher values. Using the median value results in a better representation of our measurements which is why these values are shown for comparison in Table 3 . The median values are almost by a factor of 2 lower than the mean values and are comparable to the mean values reported by Whiteway and Carswell (1994) for cases which they did not associate with stratospheric warmings.

\section{Conclusions}

An analysis of gravity wave activity as derived from wintertime temperature measurements with the Esrange lidar $\left(68^{\circ} \mathrm{N}, 21^{\circ} \mathrm{E}\right)$ between 1996 and 2014 has been presented. We found that the vertical wavelengths of the gravity waves observed during winter range from 2 to $13 \mathrm{~km}$ without a preferred wavelength. The upper and lower end of this range of values is determined by the analysis method. Analysis of the monthly mean GWPED showed that most of the gravity wave's energy dissipates well below the stratopause. Higher altitude regions show decreased dissipation rates of GWPED.
Blum and Fricke (2008) previously deduced a negative trend in gravity wave activity over Esrange. This is not reproduced when using the now 18 winter long time series of Esrange lidar measurements. However, the interannual variability of gravity wave activity shows a correlation with the occurrence of stratospheric warmings. During years with major stratospheric warmings a lower GWPED is detected than during quiet years.

The GWPED occurrence frequency shows a bimodal distribution. This suggests that two processes affect the gravity wave activity at Esrange. Based on relating the two modes to the literature we conclude that the first Gaussian mode is the result of ubiquitous wave sources whereas the second mode is associated with strong mountain wave forcing. The GWPED occurrence frequency at locations unaffected by orographic forcing is thus expected to only show a single mode. This hypothesis should be tested with measurements from those locations. A comparison with the literature on gravity wave activity also reveals that the highest values of GWPED can be found at Esrange. This is assumed to be the result of two effects. The Scandinavian mountain range upstream of the measurement site is a potential source of gravity waves with increased GWPED. In addition, GWPED is generally found to be larger at high latitudes. The latter has been inferred from both lidar measurements (see Table 1) and satellite observations (Alexander et al., 2008). Currently, there are only few long-term records of GWPED as measured with lidar. These records might furthermore be biased by the different methods of retrieving gravity wave perturbations. A standardized framework for obtaining gravity wave parameters is required to homogenize different studies and to make full use of the information provided by the few available measurements.

Acknowledgements. We thank the University Bonn and the MISU lidar team for operating and maintaining the Esrange lidar and the Esrange personnel for their support during the last 18 years.

The service charges for this open access publication have been covered by a Research Centre of the Helmholtz Association.

Topical Editor C. Jacobi thanks F. Dalaudier and one anonymous referee for their help in evaluating this paper. 


\section{References}

Achtert, P. and Tesche, M.: Assessing lidar-based classification schemes for polar stratospheric clouds based on 16 years of measurements at Esrange, Sweden, J. Geophys. Res. Atmos., 119, 1386-1405, doi:10.1002/2013JD020355, 2014.

Achtert, P., Khaplanov, M., Khosrawi, F., and Gumbel, J.: Pure rotational-Raman channels of the Esrange lidar for temperature and particle extinction measurements in the troposphere and lower stratosphere, Atmos. Meas. Tech., 6, 91-98, doi:10.5194/amt-6-91-2013, 2013.

Alexander, M. J., Gille, J., Cavanaugh, C., Coffey, M., Craig, C., Eden, T., Francis, G., Halvorson, C., Hannigan, J., Khosravi, R., Kinnison, D., Lee, H., Massie, S., Nardi, B., Barnett, J., Hepplewhite, C., Lambert, A., and Dean, V.: Global estimates of gravity wave momentum flux from High Resolution Dynamics Limb Sounder observations, J. Geophys. Res., 113, D15S18, doi:10.1029/2007JD008807, 2008.

Alexander, S. P., Klekociuk, A. R., and Murphy, D. J.: Rayleigh lidar observations of gravity wave activity in the winter upper stratosphere and lower mesosphere above Davis, Antarctica $\left(69^{\circ} \mathrm{S}, 78^{\circ} \mathrm{E}\right)$, J. Geophys. Res., 116, D13109, doi:10.1029/2010JD015164, 2011.

Behrendt, A.: Temperature Measurements with Lidar, in LIDAR: Range-Resolved Optical Remote Sensing of the Atmosphere, Springer, 2005.

Blum, U. and Fricke, K. H.: The Bonn University lidar at Esrange: technical description and capabilities for atmospheric research, Ann. Geophys., 23, 1645-1658, doi:10.5194/angeo-231645-2005, 2005.

Blum, U. and Fricke, K. H.: Indications for a long-term temperature change in the polar summer middle atmosphere, J. Atmos. Sol. Terr. Phys., 70, 123-137, doi:10.1016/j.jastp.2007.09.015, 2008.

Blum, U., Fricke, K. H., Baumgarten, G., and Schöch, A.: Simultaneous lidar observations of temperatures and waves in the polar middle atmosphere on the east and west side of the Scandinavian mountains: a case study on 19/20 January 2003, Atmos. Chem. Phys., 4, 809-816, doi:10.5194/acp-4-809-2004, 2004.

Blum, U., Fricke, K. H., Müller, K. P., Siebert, J., and Baumgarten, G.: Long-term lidar observations of polar stratospheric clouds at Esrange northern Sweden, Tellus, 57B, 412-422, 2005.

Chandran, A., Collins, R. L., and Harvey, V. L.: Stratospheremesosphere coupling during stratospheric sudden warming events, Adv. Space Res., 53, 1265-1289, 2014.

Chane-Ming, F., Molinaro, F., Leveau, J., Keckhut, P., and Hauchecorne, A.: Analysis of gravity waves in the tropical middle atmosphere over La Reunion Island $\left(21^{\circ} \mathrm{S}, 55^{\circ} \mathrm{E}\right)$ with lidar using wavelet techniques, Ann. Geophys., 18, 485-498, doi:10.1007/s00585-000-0485-0, 2000.

Duck, T. J., Whiteway, J. A., and Carswell, A. I.: Lidar observations of gravity wave activity and Arctic stratospheric vortex core warming, Geophys. Res. Lett, 25(15), 2813-2816, doi:10.1029/98GL02113, 1998.

Fritts, D. C. and Alexander, M. J.: Gravity wave dynamics and effects in the middle atmosphere, Rev. Geophys., 41, 1003, doi:10.1029/2001RG000106, 2003.

Gardner, C. S. and Taylor, M. J.: Observational limits for lidar, radar, and airglow imager measurements of gravity wave parameters, J. Geophys. Res., 103, 6427-6437, doi:10.1029/97JD03378, 1998.
Gardner, C. S., Miller, M. S., and Liu, C. H.: Rayleigh Observations of Gravity Wave Activity in the Upper Stratosphere at Urbana, Ilinois, J. Atmos. Sci., 46, 1838-1854, 1989.

Harvey, V. L., Pierce, R. B., Fairlie, T. D., and Hitchman, M. H.: A climatology of stratospheric polar vortices and anticyclones, J. Geophys. Res., 107, 4442, doi:10.1029/2001JD001471, 2002.

Hedin, A. E.: Extension of the MSIS Thermosphere Model into the middle and lower atmosphere, J. Geophys. Res., 96, 1159-1172, doi:10.1029/90JA02125, 1991.

Holton, J. R. and Alexander, M. J.: The role of waves in the transport circulation of the middle atmosphere, Geophys. Monogr., 123, 21-35, 2000.

Houghton, J. T.: The stratosphere and mesosphere, Quart. J. Roy. Meteor. Soc., 439, 1-29, doi:10.1002/qj.49710443902, 1978.

Li, T., Leblanc, T., McDermid, I. S., Wu, D. L., Dou, X., and Wang, S.: Seasonal and interannual variability of gravity wave activity revealed by long-term lidar observations over Mauna Loa Observatory, Hawaii, J. Geophys. Res., 115, D13103, doi:10.1029/2009JD013586, 2010.

Lossow, S., Khaplanov, M., Gumbel, J., Stegman, J., Witt, G., Dalin, P., Kirkwood, S., Schmidlin, F. J., Fricke, K. H., and Blum, U.: Middle atmospheric water vapour and dynamics in the vicinity of the polar vortex during the Hygrosonde-2 campaign, Atmos. Chem. Phys., 9, 4407-4417, doi:10.5194/acp-9-4407-2009, 2009.

Pautet, P.-D., Stegman, J., Wrasse, C., Nielsen, K., Takahashi, H., Taylor, M., Hoppel, K., and Eckermann, S.: Analysis of gravity waves structures visible in noctilucent cloud images, J. Atmos. Sol. Terr. Phys., 73, 2082-2090, doi:10.1016/j.jastp.2010.06.001, 2011.

Rapp, M., Strelnikov, B., Müllemann, A., Lübken, F.-J., and Fritts, D. C.: Turbulence measurements and implications for gravity wave dissipation during the MaCWAVE/MIDAS rocket program, Geophys. Res. Lett, 31, L24S07, doi:10.1029/2003GL019325, 2004.

Rauthe, M., Gerding, M., and Lübken, F.-J.: Seasonal changes in gravity wave activity measured by lidars at mid-latitudes, Atmos. Chem. Phys., 8, 6775-6787, doi:10.5194/acp-8-6775-2008, 2008.

Réchou, A., Arnault, J., Dalin, P., and Kirkwood, S.: Case study of stratospheric gravity waves of convective origin over Arctic Scandinavia - VHF radar observations and numerical modelling, Ann. Geophys., 31, 239-250, doi:10.5194/angeo-31-239-2013, 2013.

Sivakumar, V., Rao, P., and Bencherif, H.: Lidar observations of middle atmospheric gravity wave activity over a low-latitude site (Gadanki, $13.5^{\circ} \mathrm{N}, 79.2^{\circ} \mathrm{E}$ ), Ann. Geophys., 24, 823-834, doi:10.5194/angeo-24-823-2006, 2006.

Stebel, K., Barabash, V., Kirkwood, S., Siebert, J., and Fricke, K. H.: Polar mesosphere summer echoes and noctilucent clouds: Simultaneous and common-volume observations by radar, lidar, and CCD camera, Geophys. Res. Lett., 27, 661-664, doi:10.1029/1999GL010844, 2000.

Suzuki, S., Nakamura, T., Ejiri, M. K., Tsutsumi, M., Shiokawa, K., and Kawahara, T. D.: Simultaneous airglow, lidar, and radar measurements of mesospheric gravity waves over Japan, J. Geophys. Res., 115, doi:10.1029/2010JD014674, 2010.

Taori, A., Raizada, S., Ratman, M. V., Tepley, C. A., Nath, D., and Jayaraman, A.: Role of tropical convective cells in 
the observed middle atmospheric gravity wave properties from two distant low latitude stations, Earth Sci. Res., 1, 87-97, doi:10.5539/esr.v1n1p87, 2012.

Thurairajah, B., Collins, R. L., Harvey, V. L., Lieberman, R. S., Gerding, M., Mizutani, K., and Livingston, J. M.: Gravity wave activity in the Arctic stratosphere and mesosphere during the 2007-2008 and 2008-2009 stratospheric sudden warming events, J. Geophys. Res., 115, D00N06, doi:10.1029/2010JD014125, 2010a.

Thurairajah, B., Collins, R. L., Harvey, V. L., Liebermann, R. S., and Mizutani, K.: Rayleigh lidar observations of reduced gravity wave activity during the formation of an elevated stratopause in 2004 at Chatnika, Alaska $\left(65^{\circ} \mathrm{N}, 147^{\circ} \mathrm{W}\right)$, J. Geophys. Res., 115, D13 109, doi:10.1029/2009JD013036, 2010b.

Torrence, C. and Compo, G. P.: A practical guide to wavelet analysis, Bull. Amer. Meteor. Soc., 79, 61-78, 1998.

Walterscheid, R. L., Hecht, J. H., Vincent, R. A., Reid, I. M., Woithe, J., and Hickey, M. P.: Analysis and interpretation of airglow and radar observations of quasi-monochromatic gravity waves in the upper mesosphere and lower thermosphere over Adelaide, Australia $\left(35^{\circ} \mathrm{S}, 138^{\circ} \mathrm{E}\right)$, J. Atmos. Sol. Terr. Phys., 61, 461-478, doi:10.1016/S1364-6826(99)00002-4, 1999.

Whiteway, J. A. and Carswell, A. I.: Rayleigh lidar observations of thermal structure and gravity wave activity in the high arctic during a stratospheric warming, J. Atmos. Sci., 51, 3122-3136, 1994.
Whiteway, J. A. and Carswell, A. I.: Lidar observations of gravity wave activity in the upper stratosphere over Toronto, J. Geophys. Res., 100, 14113-14124, doi:10.1029/95JD00511, 1995.

Wilms, H., Rapp, M., Hoffmann, P., Fiedler, J., and Baumgarten, G.: Gravity wave influence on NLC: experimental results from ALOMAR, $69^{\circ} \mathrm{N}$, Atmos. Chem. Phys., 13, 11951-11963, doi:10.5194/acp-13-11951-2013, 2013.

Wilson, R., Chanin, M., and Hauchecorne, A.: Gravity waves in the middle atmosphere observed by Rayleigh lidar: 2. Climatology, J. Geophys. Res., 96, 5169-5183, doi:10.1029/90JD02231, 1991.

Yamashita, C., Chu, X., Liu, H., Espy, P. J., Nott, G. J., and Huang, W.: Stratospheric gravity wave characteristics and seasonal variations observed by lidar at the South Pole and Rothera, Antarctica, J. Geophys. Res., 114, D12101, doi:10.1029/2008JD011472, 2009.

Zhang, S. D. and Yi, F.: A statistical study of gravity waves from radiosonde observations at Wuhan $\left(30^{\circ} \mathrm{N}, 114^{\circ} \mathrm{E}\right)$ China, Ann Geophys., 23, 665-673, doi:10.5194/angeo-23-665-2005, 2005.

Zhang, Y., Xiong, J., Liu, L., and Wan, W.: A global morphology of gravity wave activity in the stratosphere revealed by the 8-year SABER/TIMED data, J. Geophys. Res., 117, D21101, doi:10.1029/2012JD017676, 2012. 